\title{
The Transpose-AMIP II Experiment and Its Application to the Understanding of Southern Ocean Cloud Biases in Climate Models
}

\author{
K. D. Williams, ${ }^{*}$ A. Bodas-Salcedo, ${ }^{*}$ M. Déqué,${ }^{+}$S. Fermepin, ${ }^{\#}$ B. Medeiros, ${ }^{@}$ M. Watanabe, ${ }^{\&}$ \\ C. JAKOB, ${ }^{* *}$ S. A. KLeIN,${ }^{++}$C. A. Senior, ${ }^{*}$ AND D. L. Williamson ${ }^{@}$ \\ * Met Office, Exeter, United Kingdom \\ ${ }^{+}$Météo-France/CNRM, CNRS/GAME, Toulouse, France \\ \# Institut Pierre Simon Laplace, Paris, France \\ @ National Center for Atmospheric Research, ${ }^{\# \# ~ B o u l d e r, ~ C o l o r a d o ~}$ \\ \& University of Tokyo, Tokyo, Japan \\ ** Monash University, Melbourne, Victoria, Australia \\ ${ }^{++}$Lawrence Livermore National Laboratory, Livermore, California
}

(Manuscript received 5 July 2012, in final form 17 October 2012)

\begin{abstract}
The Transpose-Atmospheric Model Intercomparison Project (AMIP) is an international model intercomparison project in which climate models are run in "weather forecast mode." The Transpose-AMIP II experiment is run alongside phase 5 of the Coupled Model Intercomparison Project (CMIP5) and allows processes operating in climate models to be evaluated, and the origin of climatological biases to be explored, by examining the evolution of the model from a state in which the large-scale dynamics, temperature, and humidity structures are constrained through use of common analyses.

The Transpose-AMIP II experimental design is presented. The project requests participants to submit a comprehensive set of diagnostics to enable detailed investigation of the models to be performed. An example of the type of analysis that may be undertaken using these diagnostics is illustrated through a study of the development of cloud biases over the Southern Ocean, a region that is problematic for many models. Several models share a climatological bias for too little reflected shortwave radiation from cloud across the region. This is found to mainly occur behind cold fronts and/or on the leading side of transient ridges and to be associated with more stable lower-tropospheric profiles. Investigation of a case study that is typical of the bias and associated meteorological conditions reveals the models to typically simulate cloud that is too optically and physically thin with an inversion that is too low. The evolution of the models within the first few hours suggests that these conditions are particularly sensitive and a positive feedback can develop between the thinning of the cloud layer and boundary layer structure.
\end{abstract}

\section{Introduction}

Over recent years there has been growing interest in using general circulation models (GCMs) across a range of time scales in order to understand the origin of key model biases (e.g., Phillips et al. 2004; Rodwell and Palmer 2007; Martin et al. 2010). Running "weather forecasts" (or more correctly hindcasts since they are

\footnotetext{
\#\# The National Center for Atmospheric Research is sponsored by the National Science Foundation.

Corresponding author address: Keith Williams, Met Office, FitzRoy Road, Exeter EX1 3PB, United Kingdom.

E-mail: keith.williams@metoffice.gov.uk
}

run retrospectively) with the atmospheric component of climate models enables detailed evaluation of the processes operating through a comparison of the model with a variety of observations for particular meteorological events (e.g., Boyle and Klein 2010). In addition, understanding the development of biases as they grow from a well-initialized state can provide significant insight into the origin of these biases, which can be used in the future development of the model (e.g., Williamson et al. 2005). Many of the principal sources of model spread in terms of simulating climate and climate change are fast processes (e.g., clouds), so examining climate models on these time scales can yield greater understanding of why their longer time-scale response differs (e.g., Williams and Brooks 2008; Xie et al. 2012). 
For those GCMs that are routinely used for both weather and climate prediction, such analysis is commonplace (Senior et al. 2010). Indeed, the benefits are leading these centers to unify the model physics and dynamics in their prediction systems to a greater extent than ever before (Brown et al. 2012). For those climate centers without their own data assimilation system, it has been suggested that many of the benefits of this type of analysis may be realized if they are initialized from an analysis produced by an operational numerical weather prediction (NWP) center. In the United States this was the basis of the Climate Change Prediction ProgramAtmospheric Radiation Measurement (CCPP-ARM) Parameterization Test Bed (CAPT) in which short-range hindcasts from the National Center for Atmospheric Research (NCAR) climate model were initialized from European Centre for Medium-Range Weather Forecasts (ECMWF) analyses (Phillips et al. 2004). (After the realignment of some programs, the CAPT acronym was changed to stand for Cloud Associated Parameterization Test Bed.)

In 2005, the Joint Scientific Committee-Commission on Atmospheric Sciences (JSC/CAS) Working Group on Numerical Experimentation (WGNE) initiated an intercomparison of climate models running a set of shortrange hindcasts and initialized from ECMWF analyses. Since WGNE originally set up the Atmospheric Model Intercomparison Project (AMIP; Gates et al. 1999) in which atmosphere GCMs were run freely for decades, these short hindcasts in which the large-scale dynamics are constrained by being initialized to a common analysis were termed "Transpose-AMIP" experiments. This set of Transpose-AMIP simulations was undertaken by a small number of centers, and a relatively limited set of diagnostics was collected, with analysis focused on the Southern Great Plains ARM site. Unfortunately, given the mix of phenomena that occurred during the period considered, the forecast sample size was too small to allow a statistically meaningful analysis. In 2008 WGNE agreed that the experiment should be extended and ideally run alongside the phase 5 of the Coupled Model Intercomparison Project (CMIP5; Taylor et al. 2012) activity organized by the Working Group on Coupled Modeling (WGCM). The Transpose-AMIP II experiment was subsequently drawn up and became jointly endorsed by WGNE and WGCM.

In this paper we describe the Transpose-AMIP II experiment (hereafter abbreviated to T-AMIP2). To date, data from five GCMs have been submitted to T-AMIP2, with more expected to be submitted over the coming years. We use T-AMIP2 data from these models to illustrate how the experiment, and the range of diagnostics collected, may be used to understand the origin of a bias common to a number of GCMs. Trenberth and Fasullo (2010) show that many GCMs are biased to have too little reflected shortwave radiation over the Southern Ocean, which they argue affects both the coupled model performance due to excess shortwave radiation reaching the ocean and the reliability of climate change projections due to a possible spurious cloud response over the region. More recently, detailed studies into the climatological structure and distribution of clouds over the Southern Ocean, and their evaluation in a particular GCM, have been carried out by Haynes et al. (2011) and Bodas-Salcedo et al. (2012). Here, we relate the climatological Southern Ocean radiation biases seen in the CMIP5 AMIP experiment with those in T-AMIP2 and use a case-study approach to gain a greater understanding of possible causes.

In the next section we describe the T-AMIP2 experiment and diagnostics collected. The models and observational data used in the subsequent analysis are presented in section 3. In section 4 the meteorological situations in which the biases are largest in the AMIP and T-AMIP2 experiments are discussed. Results from a T-AMIP2 case study that has typical meteorological conditions in which the bias is present are shown in section 5, while conclusions are given in section 6 .

\section{Transpose-AMIP II}

\section{a. Experimental design}

The latest information on T-AMIP2 is available online (see http://www.transpose-amip.info). Here we document the key details of the T-AMIP2 experimental design.

T-AMIP2 comprises 64 hindcasts using a center's atmospheric GCM (AGCM), each hindcast being five days in length. The hindcasts are split into four sets. The full list of hindcast start times is given in Table 1. The hindcast start times in each set are at 30-h intervals to ensure sampling throughout the diurnal cycle for each grid point for a given lead time. This is particularly important for some diagnostics that are only available at sunlit points. The 2008/09 period was chosen to tie in with the Year of Tropical Convection (YOTC; Waliser et al. 2012) during which ECMWF analyses have been made generally available to the research community and various field campaigns and other modeling studies are being undertaken. The four sets of hindcasts were chosen to evenly sample the annual cycle while also providing several hindcasts within one or more of the intensive observation periods (IOPs) for the Variability of the American Monsoon Systems (VAMOS) Ocean-CloudAtmosphere-Land Study (VOCALS), Asian Monsoon 
TABLE 1. List of start times for the T-AMIP2 hindcasts. (All times are in UTC.)

\begin{tabular}{|c|c|c|c|}
\hline 000015 Oct 2008 & 000015 Jan 2009 & 000015 Apr 2009 & 000015 Jul 2009 \\
\hline 060016 Oct 2008 & 060016 Jan 2009 & 060016 Apr 2009 & 060016 Jul 2009 \\
\hline 120017 Oct 2008 & 120017 Jan 2009 & 120017 Apr 2009 & 120017 Jul 2009 \\
\hline 180018 Oct 2008 & 180018 Jan 2009 & 180018 Apr 2009 & 180018 Jul 2009 \\
\hline 000020 Oct 2008 & 000020 Jan 2009 & 000020 Apr 2009 & 000020 Jul 2009 \\
\hline 060021 Oct 2008 & 060021 Jan 2009 & 060021 Apr 2009 & 060021 Jul 2009 \\
\hline 120022 Oct 2008 & 120022 Jan 2009 & 120022 Apr 2009 & 120022 Jul 2009 \\
\hline 180023 Oct 2008 & 180023 Jan 2009 & 180023 Apr 2009 & 180023 Jul 2009 \\
\hline 000025 Oct 2008 & 000025 Jan 2009 & 000025 Apr 2009 & 000025 Jul 2009 \\
\hline 060026 Oct 2008 & 060026 Jan 2009 & 060026 Apr 2009 & 060026 Jul 2009 \\
\hline 120027 Oct 2008 & 120027 Jan 2009 & 120027 Apr 2009 & 120027 Jul 2009 \\
\hline 180028 Oct 2008 & 180028 Jan 2009 & 180028 Apr 2009 & 180028 Jul 2009 \\
\hline 000030 Oct 2008 & 000030 Jan 2009 & 000030 Apr 2009 & 000030 Jul 2009 \\
\hline 060031 Oct 2008 & 060031 Jan 2009 & 06001 May 2009 & 060031 Jul 2009 \\
\hline 12001 Nov 2008 & 12001 Feb 2009 & 12002 May 2009 & 12001 Aug 2009 \\
\hline 18002 Nov 2008 & 18002 Feb 2009 & 18003 May 2009 & 18002 Aug 2009 \\
\hline
\end{tabular}

Years (AMY), and The Observing System Research and Predictability Experiment (THORPEX) Pacific Asian Regional Campaign (T-PARC).

Model state variables are initialized from ECMWF YOTC analyses. Centers are advised to interpolate the analysis onto their model grid following the ECMWF Integrated Forecast System documentation (see http:// www.ecmwf.int/research/ifsdocs_old/TECHNICAL/). Atmospheric composition, solar forcing, and land use are as 2008/09 of the CMIP5 AMIP experiment. It is recommended that sea surface temperatures from the ECMWF YOTC analyses persist in the hindcasts.

The longer time scale over which processes in land surface models operate, compared with the atmosphere, means that a straight transplant of initial conditions from an analysis produced by a different land surface model may not always be appropriate (e.g., Boyle et al. 2005). However, feedback from modeling centers in the planning stages of T-AMIP2 indicated that being overly prescriptive on the land surface initialization may deter centers from participating. While for some studies the choice of land surface initialization will be important, for others (such as the study presented in this paper) it is less so. It was therefore decided to allow a choice of land surface initialization from the following methods, while requesting that participants clearly indicate which methodology they have used:

- Initialize from fields produced by a land surface assimilation system [e.g., ECMWF or Global Land Data Assimilation Systems (GLDAS)];

- Initialize using a suitable climatology [e.g., from the Global Soil Wetness Project 2 (GSWP2) or derived from the model's AMIP simulation]; or

- Initialize with a nudging method as described by Boyle et al. (2005).
Aerosol concentrations are either initialized using a climatology calculated from the model's AMIP simulation or initialized using the nudging method of Boyle et al. (2005). Nonstate variable prognostics that spin up quickly (such as cloud fraction for models with a prognostic scheme) can either be initialized from zero or initialized using the nudging method of Boyle et al. (2005).

To use the T-AMIP2 experiment to comment on the processes operating in the climate change simulations of CMIP5, the AGCMs submitted to T-AMIP2 are requested to be identical, in terms of both the model physics/dynamics and resolution, to those used for the CMIP5 AMIP experiment. While maximum benefit from the project is expected for climate models, T-AMIP2 is also open to NWP centers to participate. WGNE encouraged NWP centers to run and submit an AMIP simulation for CMIP5 and any centers undertaking this experiment are asked to also submit to T-AMIP2.

To test the sensitivity of the results to the choice of analysis, centers are given the option to also submit a second set of T-AMIP2 hindcasts using an alternative initialization. For this optional set of hindcasts, centers with their own assimilation system will use their own analyses while centers without their own assimilation system are asked to initialize from the Global Modeling and Assimilation Office (GMAO) Modern-Era Retrospective Analysis for Research and Applications (MERRA; Rienecker et al. 2011).

\section{b. Requested diagnostics and data access}

A key aim of T-AMIP2 is that it should allow detailed diagnostic analysis of the processes operating in the model. As such, a comprehensive set of diagnostics are requested at high temporal resolution. All of the requested diagnostics appear within the CMIP5 diagnostic lists, 
so no new diagnostics need to be especially produced for T-AMIP2.

The full details of the requested diagnostics can be found under the "Data requirements" section (http:// www.transpose-amip.info), but they include the following:

- All single level and multilevel (both model level and standard pressure level) fields that are usually collected as monthly means in an AMIP experiment are requested as 3-h means through the T-AMIP2 hindcasts.

- All fields normally used for standard NWP verification [e.g., in calculating Commission for Basic Systems (CBS) scores].

- The 3-h mean temperature and humidity tendencies on model levels from various sections of the model physics/dynamics.

- Output from the Cloud Feedback Model Intercomparison Project (CFMIP) Observation Simulator Package (COSP; Bodas-Salcedo et al. 2011), which produces model diagnostics that emulate several satellite products including the International Satellite Cloud Climatology Project (ISCCP), CloudSat, and Cloud-Aerosol Lidar and Infrared Pathfinder Satellite Observations (CALIPSO). CloudSat and CALIPSO are part of the National Aeronautics and Space Administration (NASA) A-Train, and T-AMIP2 requests curtain data from the models that match the satellite orbit.

- At 119 sites identified by the CFMIP project, many of the above diagnostics, including model tendencies, are requested at 30-min intervals through the hindcast, which for many climate models is close (or equal) to the model time step. This allows detailed examination of the model evolution through the hindcast. The sites (listed at http://www.cfmip.net) include ARM and CloudNet (Illingworth et al. 2007), as well as points along transects including the Global Energy and Water Cycle Experiment (GEWEX) Cloud Systems Study (GCSS) Pacific cross section (GPCI), the VOCALS cross section, and the African Monsoon Multidisciplinary Analyses (AMMA) cross section.

The format of, and access to, data from T-AMIP2 follows CMIP5 with all submitted data being Climate Forecast (CF)-compliant network Common Data Form (netCDF) and conforming to the standards of the Climate Model Output Rewriter (CMOR; Taylor et al. 2012). T-AMIP2 data are freely available for research purposes and can be downloaded from the Earth System Grid Federation (ESGF) (e.g., http://pcmdi3.llnl.gov/ esgcet), identical to CMIP5 except for selecting the project to be "TAMIP."

The breadth of the diagnostic list (designed for comparison with observational data) and the experimental period tying in with several field campaigns means that a wide variety of scientific studies may be undertaken with the data. In addition to the present study, proposed diagnostic subprojects include the relationship between short and long time-scale model errors, intense extratropical windstorms, VOCALS analysis, and water budget analysis. We encourage the scientific research community to make use of the T-AMIP2 data and submit subproject summaries of the analysis they wish to undertake.

\section{Models and observational data}

At the time of submission (5 July 2012), output from five models had been submitted to T-AMIP2. These are summarized in Table 2 (which also provides expansions of model acronyms).

A range of observational data is used in this study. Mean top-of-atmosphere (TOA) fluxes from AMIP simulations are compared with Clouds and the Earth's Radiant Energy System-Energy Balanced and Filled (CERES-EBAF) data (Loeb et al. 2009). Daily TOA fluxes are evaluated against CERES-Flashflux (Wielicki et al. 1996), ISCCP-FD (Zhang et al. 2004), and Earth Radiation Budget Experiment (ERBE; Barkstrom and Smith 1986) datasets.

Cloud comparisons are made against the ISCCP D1 dataset (Rossow and Schiffer 1999), which comprises 3 -hourly histograms of cloud fraction on a $2.5^{\circ}$ grid in seven cloud-top pressure and six optical depth bins. The lidar backscatter from clouds along a section of the A-Train orbit is presented from CALIPSO (Winker et al. 2010). This uses a nadir-pointing instrument with a beam diameter of $70 \mathrm{~m}$ at the earth's surface and produces footprints every $333 \mathrm{~m}$ in the along-track direction. We use the GCM-oriented CALIPSO cloud product (Chepfer et al. 2010) and comparison with the model is through height-scattering ratio histograms of cloud amount.

\section{Nature of the Southern Ocean cloud biases}

The climatological bias in TOA reflected shortwave (RSW) and outgoing longwave radiation (OLR) over the Southern Ocean region is obtained from the CMIP5 AMIP experiment. Here, we focus on those models that have submitted both their AMIP and T-AMIP2 experiments (Fig. 1). During most of the year, the bias in RSW is considerably larger than that in OLR. The models show the largest bias in RSW during the austral summer when insolation is at a maximum. For three of the models (CNRM-CM5, HadGEM2-A, and MIROC5), there is a negative bias in RSW that reaches a peak from -30 to $-45 \mathrm{~W} \mathrm{~m}^{-2}$ between $60^{\circ}$ and $65^{\circ} \mathrm{S}$. This is a common 
TABLE 2. Summary information for each model. The horizontal resolution for gridpoint models is given using the $N$ notation, denoting half the number of longitudinal grid points. Since a wave cannot be represented with less than two grid points, this allows approximate comparison with $T$ notation for spectral models. The approximate midlatitude resolution is also given in $\mathrm{km}$. Here $L$ denotes the number of levels. The methods used for initialization of the land surface, cloud, and aerosols are also given.

\begin{tabular}{|c|c|c|c|}
\hline Center/model & Reference & Resolution & Initialization \\
\hline $\begin{array}{l}\text { NCAR/Community Climate System } \\
\text { Model, version } 4 \text { (CCSM4) }\end{array}$ & $\begin{array}{l}\text { Gent et al. (2011); } \\
\quad \text { Neale et al. (2010) }\end{array}$ & N144 $(90 \mathrm{~km}) \mathrm{L} 26$ & $\begin{array}{l}\text { Land surface and clouds initialized from a } \\
\text { spun-up state following Boyle et al. (2005); } \\
\text { climatological aerosol concentrations. }\end{array}$ \\
\hline $\begin{array}{l}\text { Centre National de Recherches Mé- } \\
\text { téorologiques (CNRM)-CERFACS/ } \\
\text { CNRM-Coupled Global Climate } \\
\text { Model, version } 5 \text { (CNRM-CM5) }\end{array}$ & Voldoire et al. (2013) & TL127 (160 km) L31 & $\begin{array}{l}\text { Land surface interpolated from } \\
\text { ERA-Interim; clouds are uninitialized; } \\
\text { climatological aerosol concentrations. }\end{array}$ \\
\hline $\begin{array}{l}\text { Met Office/Hadley Centre Global } \\
\text { Environmental Model, version 2- } \\
\text { Atmosphere only (HadGEM2-A) }\end{array}$ & Martin et al. (2011) & N96 (135 km) L38 & $\begin{array}{l}\text { Land surface initialized from MO analysis; } \\
\text { clouds are uninitialized; climatological } \\
\text { aerosol concentrations. }\end{array}$ \\
\hline $\begin{array}{l}\text { L'Institut Pierre-Simon Laplace } \\
\text { (IPSL)/IPSL Coupled Model, } \\
\text { version 5A-LR } \\
\text { (IPSL-CM5A-LR) }\end{array}$ & http://icmc.ipsl.fr & N48 (270 km) L39 & $\begin{array}{l}\text { Land surface fields use AMIP climatology; } \\
\text { clouds are uninitialized; climatological } \\
\text { aerosol concentrations. }\end{array}$ \\
\hline $\begin{array}{l}\text { Model for Interdisciplinary Research } \\
\text { on Climate, version } 5 \text { (MIROC5) }\end{array}$ & Watanabe et al. (2010) & T85 (150 km) L40 & $\begin{array}{l}\text { Land surface, clouds, and aerosols initialized } \\
\text { from a spun-up state following Boyle et al. } \\
\text { (2005) }\end{array}$ \\
\hline
\end{tabular}

bias among many of the CMIP5 AMIP simulations and is qualitatively consistent with the CMIP3 coupled model results presented in Trenberth and Fasullo (2010). CCSM4 also shows a negative bias in RSW, but covering a broader range of latitudes with a peak much farther north $\left(45^{\circ} \mathrm{S}\right)$. IPSL-CM5A-LR has a positive bias in RSW over the region, peaking at $50^{\circ} \mathrm{S}$ and, across the region as a whole, has the largest positive RSW bias. Differences in the clear-sky RSW (not shown) between these models are small, suggesting that clouds are largely responsible for these biases, and the RSW bias being larger than the OLR bias points toward low clouds being the main cause. In this paper we focus on the common negative RSW bias between $60^{\circ}$ and $65^{\circ} \mathrm{S}$.

The meteorology of the Southern Ocean is characterized by relatively fast moving synoptic depressions with their associated frontal systems, interspersed with transient ridges; hence, the cloud climatology for the region is formed from a wide variety of cloud types. It is difficult to establish from climatological means in which of these synoptic conditions the RSW bias is most prevalent. We therefore follow the cyclone compositing methodology of Field and Wood (2007), recently applied to Southern Ocean clouds by Bodas-Salcedo et al. (2012), to establish the location of the maximum bias in an average cyclone. Cyclone centers are identified from five austral summers [December-February (DJF)] of daily mean sea level pressure (MSLP) fields from the AMIP simulation. A box covering $90^{\circ}$ longitude and $30^{\circ}$ latitude centered on the cyclone is identified with the model RSW field over the region of the box being saved.
The individual cyclone boxes are then averaged. These boxes cover a reasonably large area, particularly longitudinally, to encompass not just the depression but also the surrounding environment including the typical transient ridges both ahead of and following the depression. As such, the majority of grid points are included at least once in the cyclone composite. We also conduct the cyclone compositing on MSLP data from ECMWF reanalyses and use this in conjunction with the RSW fields from ISCCP-FD and ERBE to form an observed RSW cyclone composite. The difference between the model and observed mean RSW fields provides the mean bias around the composite cyclone (Fig. 2). The position of fronts on any one cyclone on an individual day will vary, but the schematic on Fig. 2 shows the typical location.

For CNRM-CM5, HadGEM2-A, and MIROC5, the negative bias in the AMIP RSW exists around much of the composite cyclone (except the cyclone center). It is a maximum within the southwesterly flow on the cold air side of the cyclone, which could also be on the leading side of a following transient ridge. The bias also extends around the southern side of the cyclone, although the geographical area of the south side of the composite is smaller. This region of the composite cyclone will not be considered further in this paper, but it is noted that the bias here may be related to different processes. The bias is smaller in the northeast quadrant of the composite cyclone, the region typically occupied by fronts, and near the cyclone center, suggesting that these cloud systems are not generally responsible for the negative RSW bias. This picture of the bias being a maximum on the cold-air side 


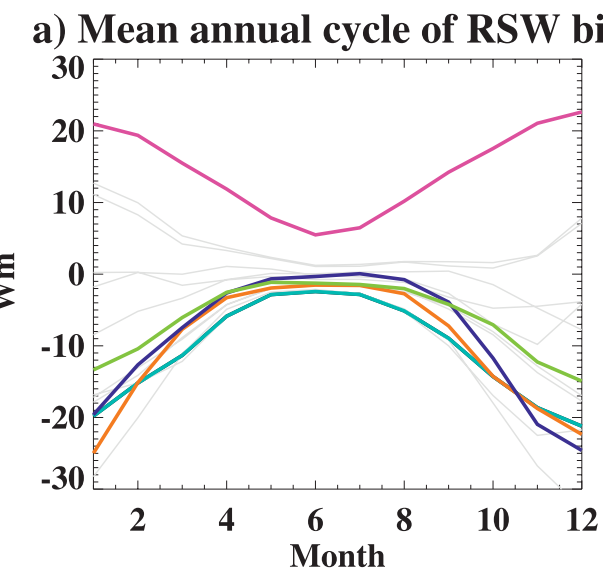

c) Zonal mean RSW bias

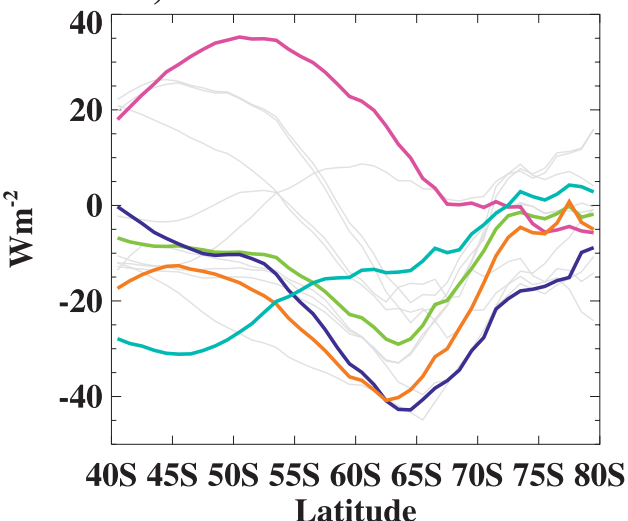

b) Mean annual cycle of OLR bias

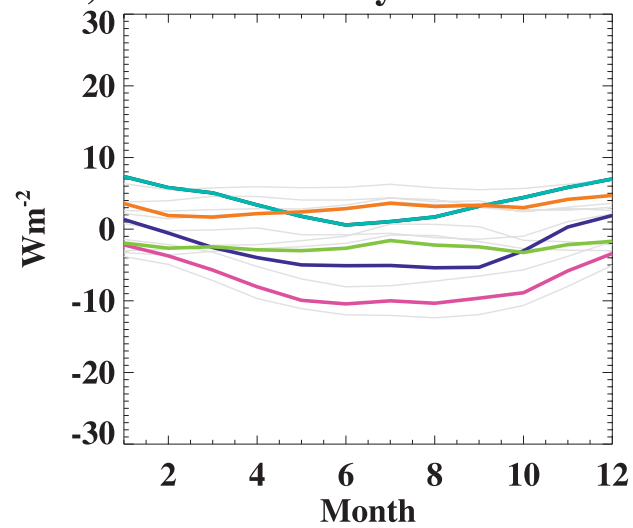

d) Zonal mean OLR bias

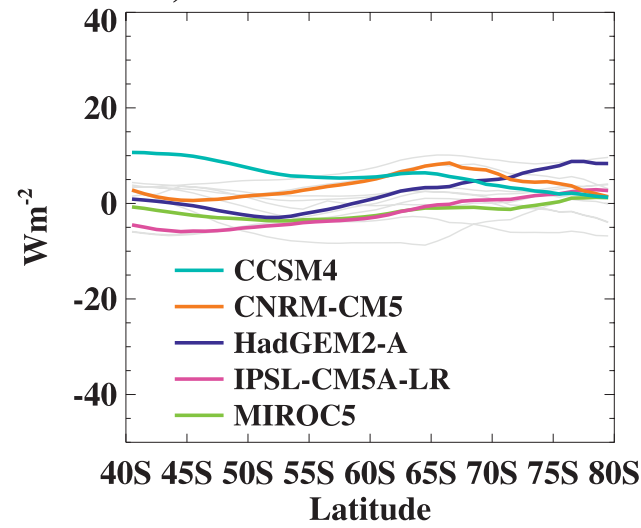

FIG. 1. Mean bias in RSW and OLR in AMIP simulations compared with CERES-EBAF. (a),(b) Monthly mean biases over all longitudes between $40^{\circ}$ and $80^{\circ} \mathrm{S}$. (c),(d) Mean DJF bias as a function of latitude. Colored lines are models that have also submitted to T-AMIP2. Gray lines show other CMIP5 AMIP models.

of the cyclone away from fronts is consistent with the findings of Bodas-Salcedo et al. (2012) when examining the Met Office model, and a bias being associated with transient ridges consistent is consistent with Norris and Weaver (2001). The cyclone composite RSW bias pattern for IPSL-CM5A-LR is structurally similar but systematically more positive, with the positive RSW bias in this model being mainly associated with frontal systems with a near-zero bias in the cold-air region.

The right-hand column of Fig. 2 shows the RSW bias from a similar cyclone compositing from each member of the January/February 2009 set of hindcasts from T-AMIP2. To be parallel to the processing of the AMIP data, the section of each hindcast used is the first full 0000-0000 UTC period that is at least $6 \mathrm{~h}$ into the hindcast and is referred to here as day 2 of the hindcast. Because of the variation in the start time in the T-AMIP2 hindcasts, this means the lead time being analyzed will vary slightly. Although the plots are noisier because of only 16 days being considered rather than approximately 450 from the AMIP simulation, the same picture of a maximum in the negative bias in RSW on the coldair side of the cyclone emerges, indicating that the bias develops early in the model simulation and can be investigated using the T-AMIP2 experiments.

The T-AMIP2 cyclone composite for CCSM4 shows one of the largest negative RSW biases among the models (the required daily diagnostics were not available from this model for the AMIP simulations). Given that the location of the cyclones will be well constrained in the T-AMIP2 experiments, this is perhaps surprising since the mean RSW bias for CCSM4 is smaller than for the other GCMs in the storm-track region of Fig. 1c. This can be understood from Fig. 3, which shows the mean evolution in RSW during the January/February 2009 hindcasts. Since the models are starting from ECMWF analyses they will typically need to spin up cloud. This happens relatively quickly and most models achieve their final mean RSW within a few hours, and certainly within the first day. The exception is CCSM4, which takes around 3 days for the RSW to reach equilibrium and on the second day (when the analysis for 

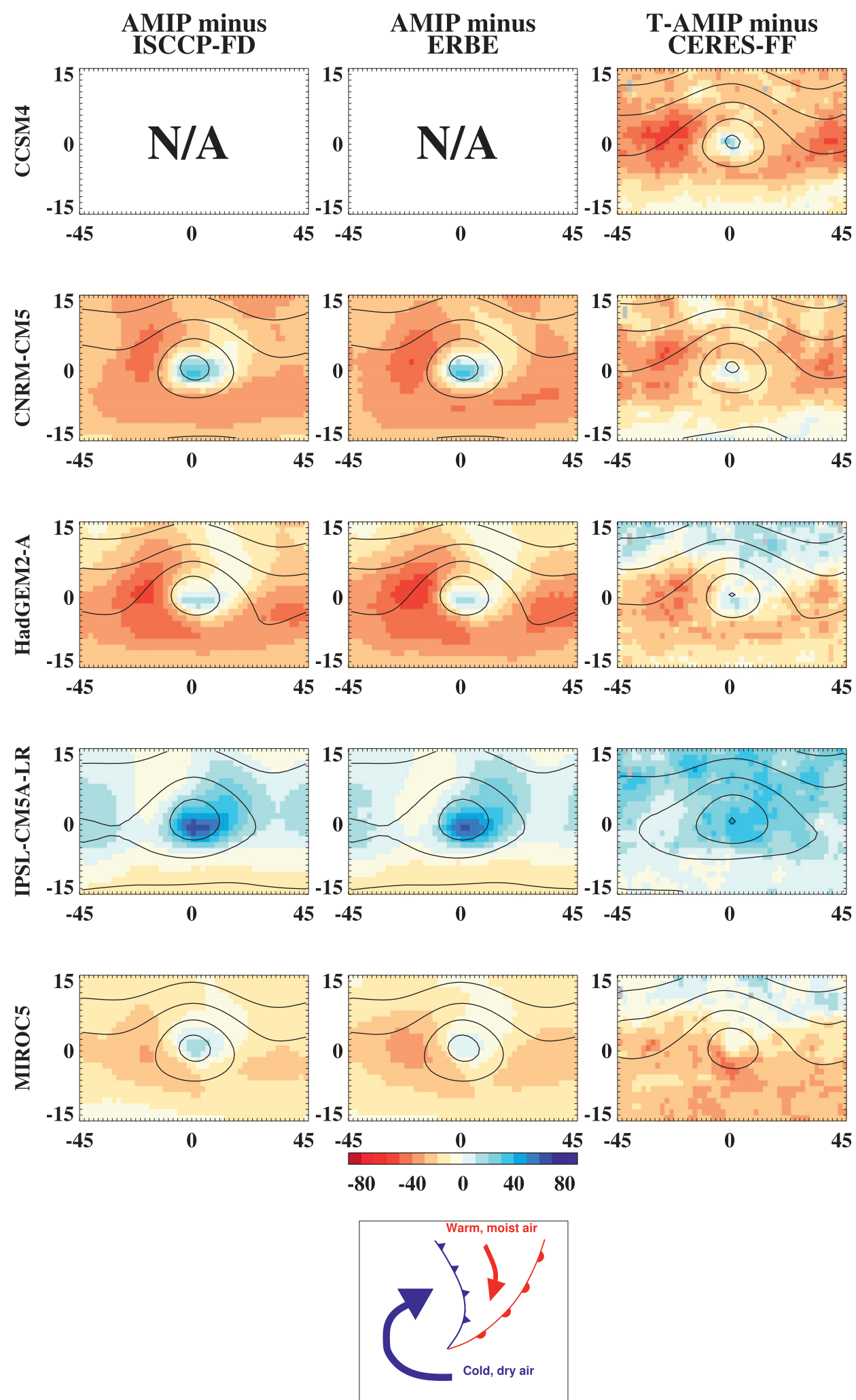

FIG. 2. Mean bias in RSW for the composite cyclone over the Southern Ocean region during DJF. Contours show model mean MSLP at 8-hPa intervals. (left) RSW bias in AMIP simulations versus ISCCP-FD. (middle) RSW bias in AMIP simulations versus ERBE. (right) Day 2 RSW bias in January/February T-AMIP2 hindcasts versus CERES-Flashflux. Also shown is a schematic illustrating the typical position of synoptic features in a Southern Hemisphere cyclone. (These diagnostics were unavailable for the CCSM4 AMIP simulation.) 

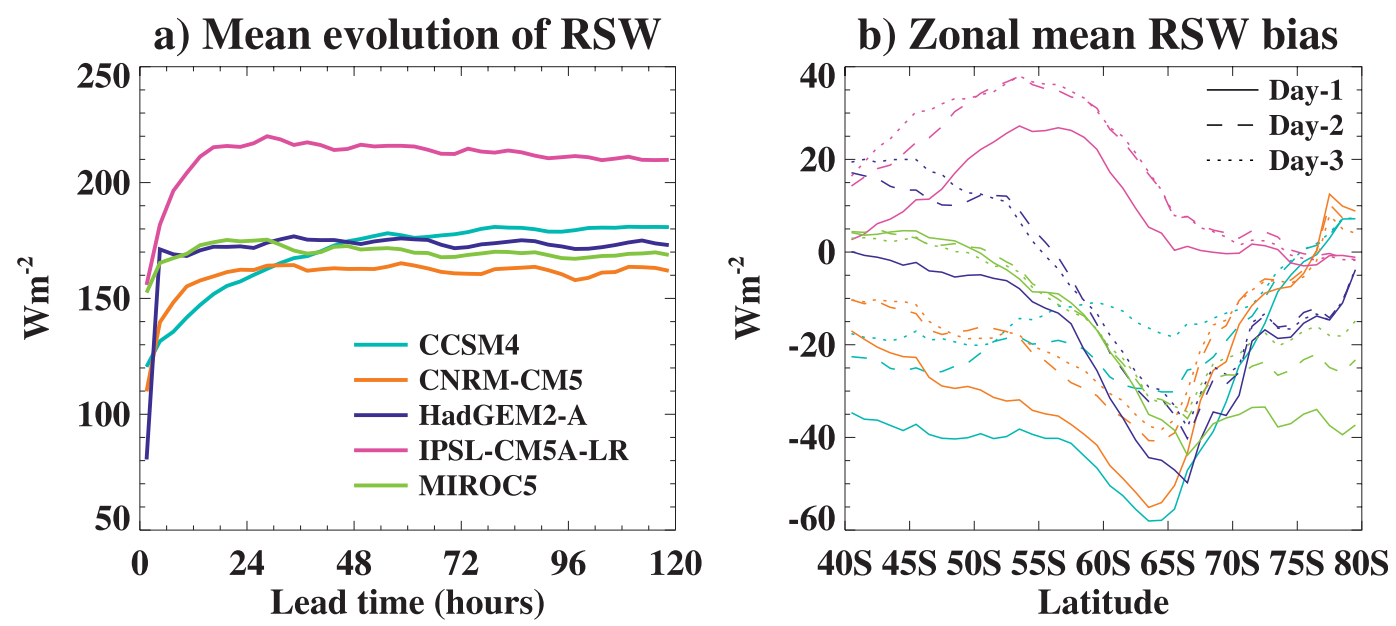

FIG. 3. (a) Mean evolution of RSW through the January/February 2009 T-AMIP2 hindcasts over the Southern Ocean region $\left(55^{\circ}-70^{\circ} \mathrm{S}\right)$. (b) Zonal mean RSW bias against CERES-Flashflux for each of the first three days of the January/February 2009 hindcasts.

Fig. 2 is undertaken) has an RSW bias between $60^{\circ}$ and $65^{\circ} \mathrm{S}$, which is comparable with most of the other models. Given the similarity with the other models in Fig. 2, we suggest that CCSM4 develops the same negative bias early on in the hindcasts, but there are then additional processes that further affect the cloud over several days and result in the different climatological RSW bias seen in Fig. 1c. A longer time scale for the development of climatological cloud biases in the NCAR model was also noted by Zhang et al. (2010) and Medeiros et al. (2012), in contrast to the rapid development of the cloud biases in the Met Office model (Williams and Brooks 2008).

To further establish the meteorological conditions under which the negative RSW bias is present, we composite each model grid point from the second day of each of the January/February 2009 hindcasts according to the model $10-\mathrm{m}$ wind speed and a measure of lower-tropospheric stability (LTS). Here we follow Williams et al. (2006) by using the difference in saturated equivalent potential temperature $\theta_{\mathrm{es}}$ between $700 \mathrm{hPa}$ and the surface. Figure 4 shows the mean RSW bias in each bin weighted by the total area of all the grid points included in that bin, such that averaging across the histograms will give the mean RSW bias from the models for the Southern Ocean region.

There is a clear dependence of the RSW bias on the LTS with the strong negative bias in most models being present in stable conditions, and the positive bias in IPSL-CM5A-LR being a maximum when the LTS is around zero. Although a more stable lower troposphere may generally be considered to be associated with calm conditions, it can be seen that the negative RSW bias occurs across a range of wind speeds and, in the more stable situations where the LTS is greater than $10 \mathrm{~K}$ in
CNRM-CM5 and MIROC5, the maximum bias is associated with relatively strong daily-mean 10-m wind speeds of around $10 \mathrm{~m} \mathrm{~s}^{-1}$. These situations of a more stable lower troposphere but strong surface flow are consistent with the region identified in the cyclone compositing as contributing the most to the RSW bias, where the advancing ridge is leading to subsidence and strong inversion above a relatively turbulent boundary layer in the strong southwesterly flow.

\section{T-AMIP2 case study analysis}

\section{a. Cloud evaluation}

We have searched through the second day of the January/February T-AMIP2 hindcasts to identify typical cases matching the meteorological conditions under which the RSW bias is a maximum. Several have been identified (not shown), of which a region of the Atlantic sector of the Southern Ocean on 17 January 2009 is typical and will be analyzed in detail here since there was also a pass of the A-Train that coincided with the bias being present. Cases similar to the one presented here occurred frequently in the hindcasts with the RSW biases being very similar.

Figure 5 shows the Met Office synoptic analysis for 1200 UTC 17 January 2009. A cold front has just passed the prime meridian associated with a depression centered near $74^{\circ} \mathrm{S}, 24^{\circ} \mathrm{W}$. Behind is a region of cold advection in a strong southwesterly flow that is also the leading side of a transient ridge.

The MSLP from each model for the T-AMIP2 hindcast initialized at 0600 UTC 16 January and verifying at 1200 UTC 17 January 2009 is generally in good agreement 
CCSM4

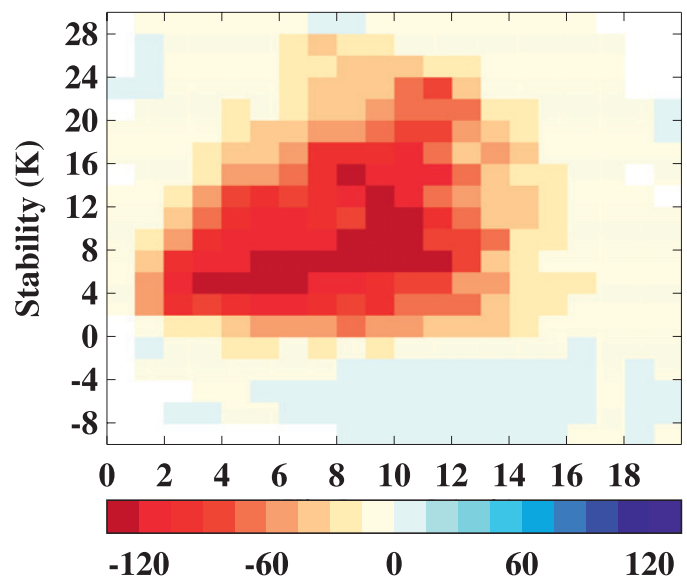

HadGEM2-A
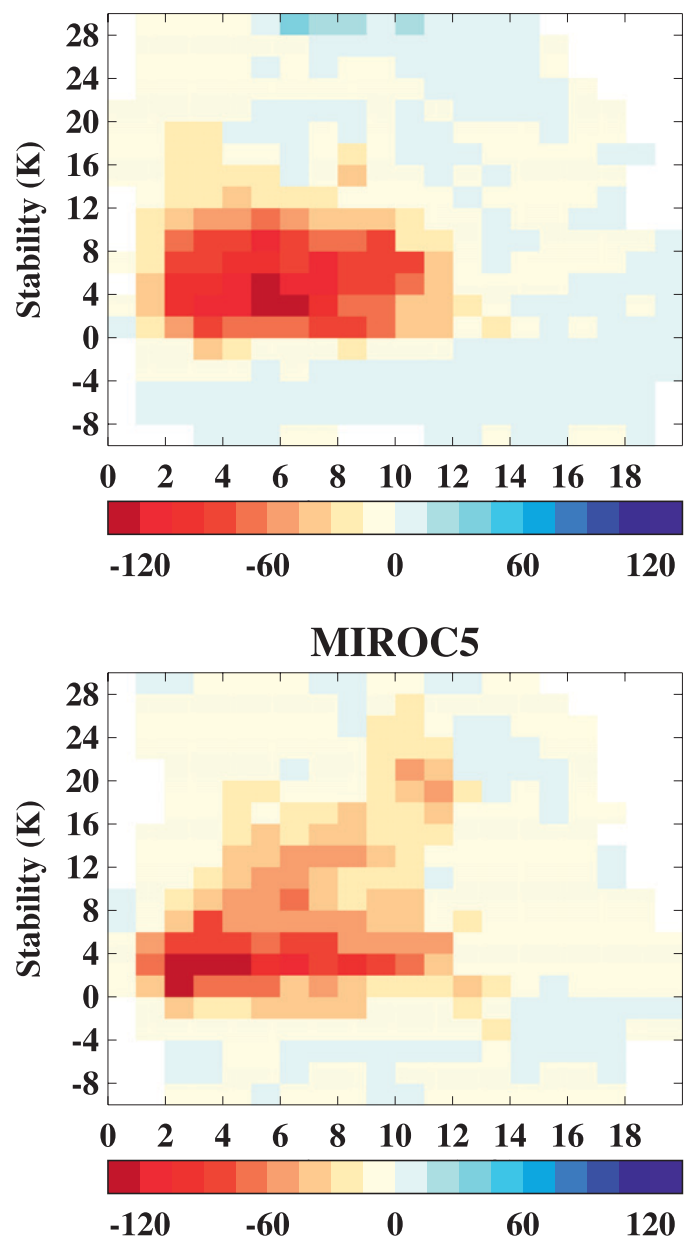

with the synoptic analysis (Fig. 6). This indicates that the large-scale dynamics are generally well constrained for this analysis as would be expected $30 \mathrm{~h}$ into a hindcast. There is a large negative RSW bias for the second day (17 January) of this hindcast in all of the T-AMIP2
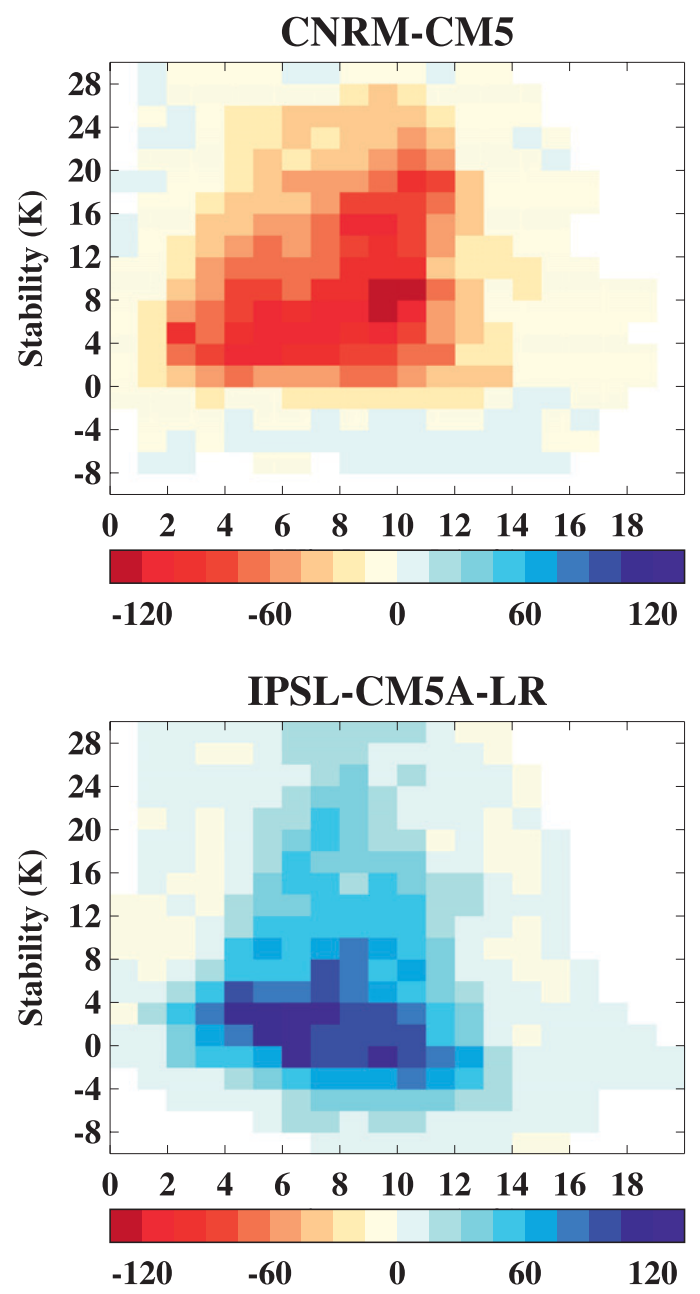

FIG. 4. Histograms of mean area-weighted RSW bias against CERES-Flashflux, binned according to $10-\mathrm{m}$ wind speed and LTS. Day 2 mean values for each grid point from the January/February hindcasts over the Southern Ocean region $\left(55^{\circ}-70^{\circ} \mathrm{S}\right)$ are used. Points beyond the limits of the axes are included within the final bin shown.

models in the region behind the cold front (marked with a dotted box), which will be investigated here. Despite its overall positive RSW bias, IPSL-CM5A-LR is consistent with the other GCMs in having a negative bias for the case study region, although it is smaller in magnitude 


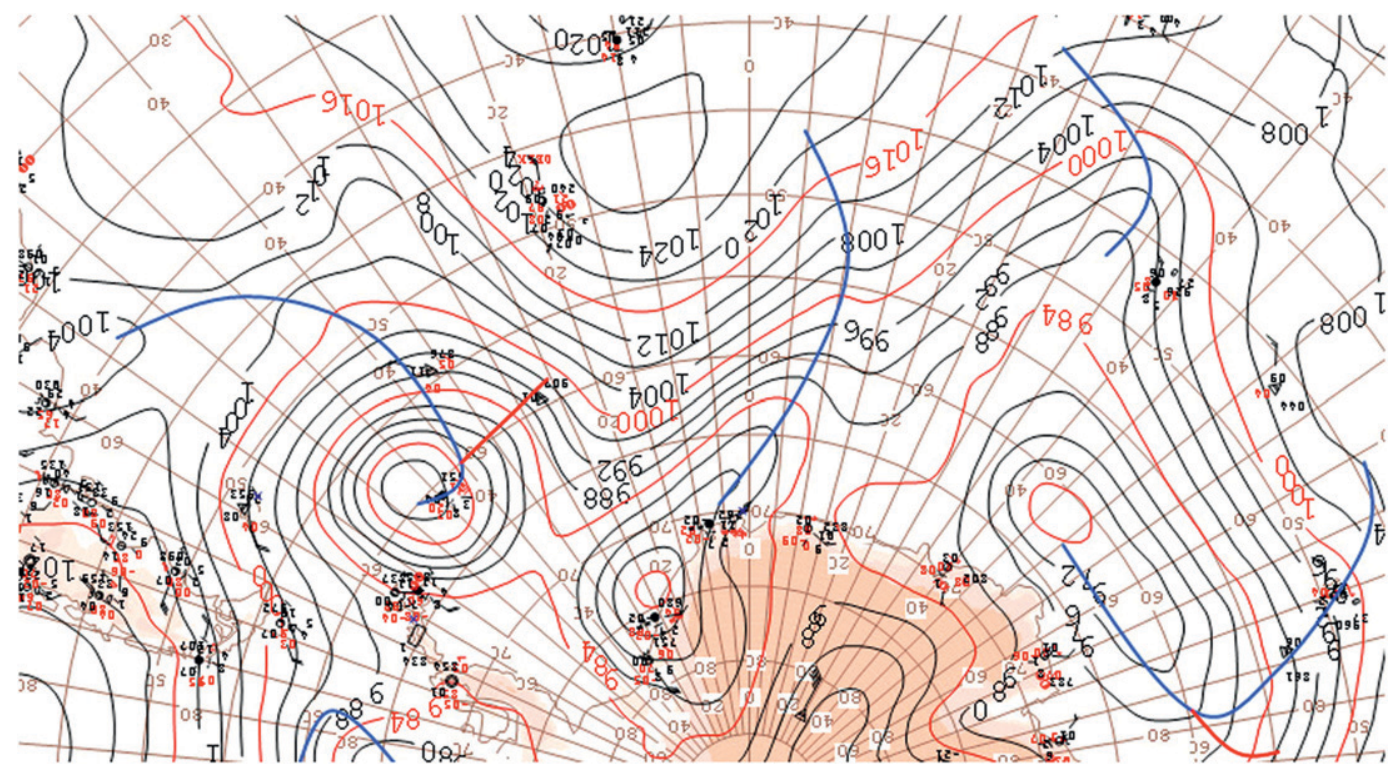

FIG. 5. Met Office surface synoptic analysis for the Atlantic sector of the Southern Ocean valid at 1200 UTC 17 Jan 2009. Contours show MSLP at 4-hPa intervals. Thicker red and blue lines mark positions of warm and cold fronts respectively. (The analysis has been inverted to aid comparison with subsequent figures).

than for the other models. The region marked with the box is typical of the meteorological conditions associated with a high RSW bias identified in Fig. 2 (post-cold front in a region of southwesterly flow) and Fig. 4 (stable conditions with a reasonably strong surface flow). The location of this region, centered at $61^{\circ} \mathrm{S}$, is also consistent with the latitude of the largest negative RSW bias in Figs. 1c and $3 \mathrm{~b}$.

In addition to the core set of hindcasts initialized from ECMWF analyses, the T-AMIP2 experimental design has an option to also submit a second set of hindcasts initialized from alternative analyses. HadGEM2-A has also been submitted with a set of hindcasts initialized from Met Office analyses (Fig. 6). While there are some differences in the RSW bias, for the region being investigated here there is very little difference between the hindcasts, indicating that the choice of analysis is not a factor in the development of this bias.

The mean cloud fraction histogram from ISCCP for 1200 UTC 17 January over the dotted box in Fig. 6 is shown in Fig. 7, together with the comparable COSP output from the models $30 \mathrm{~h}$ into the hindcast and verifying at the same time as the observations. There is $100 \%$ cloud cover over the region in the observations, with a large proportion having tops between 560 and $680 \mathrm{hPa}$ and optical depths between 23.0 and 60.0. The models have slightly lower cloud fractions than observed (much lower in the case of CCSM4), and all have smaller optical depths (typically between 3.6 and 9.4) with the low-cloud tops being mostly at a lower altitude.
An alternative evaluation of the cloud may be obtained from instruments on the A-Train that passed over the region along the dashed line in Fig. 6 at around 1420 UTC 17 January. The cloud radar on CloudSat is generally not able to resolve cloud below $1 \mathrm{~km}$ in altitude because of ground clutter. There was also no signal from the low cloud above $1 \mathrm{~km}$ present in this case, suggesting that it was nonprecipitating. Instead we compare the model with data from the CALIPSO lidar. Figure 8a shows the lidar backscatter ratio along the transect, cutting the cold front at either end of the cross section. During this period, the lidar had intermittent faults resulting in many "missing data" columns in the curtain data. However, a layer of continuous low cloud can still be clearly seen through the center of the transect with the cloud-top altitude decreasing from around $3 \mathrm{~km}$ at the southern end to $1.5 \mathrm{~km}$ at the northern end.

The central section of this transect has been processed into an altitude-scattering ratio histogram (Fig. 8b). The lidar is sensitive to optically very thin cloud and the histogram shows that a small amount of very thin cloud is present on occasions through much of the troposphere. However, the majority of the cloud in the central region of the transect has cloud tops between 1.5 and $3 \mathrm{~km}$ with scattering ratios in excess of 80 , indicating that the cloud is highly reflective. This is consistent with the high optical depths seen in the ISCCP observations (Fig. 7) and the agreement between these two independent, and quite different, observations provides confidence in the cloud properties present at the time. 


\section{CCSM4}

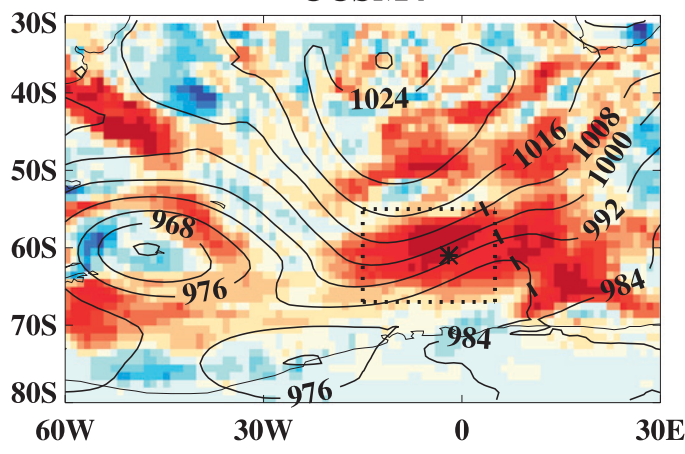

HadGEM2-A

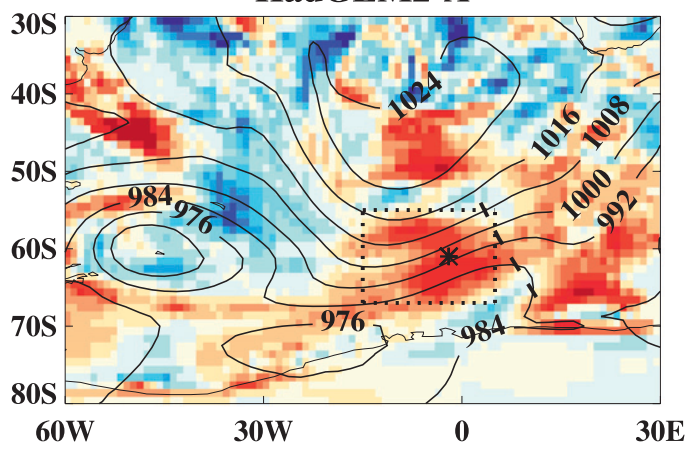

IPSL-CM5A-LR

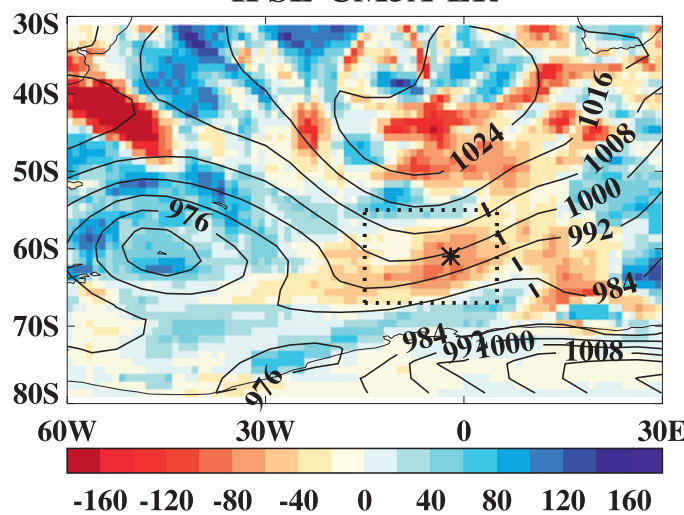

CNRM-CM5

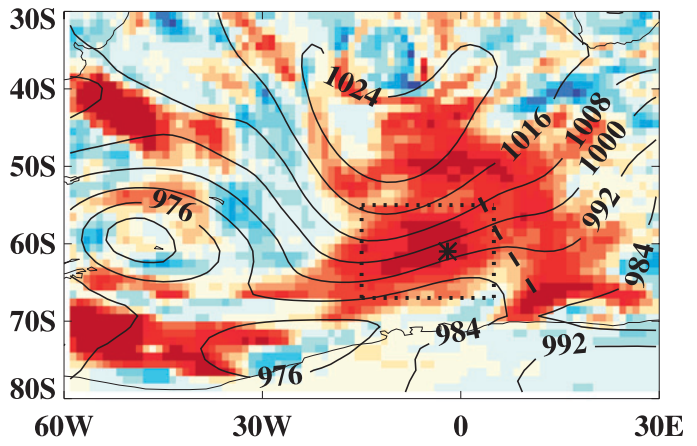

HadGEM2-A from MO analysis

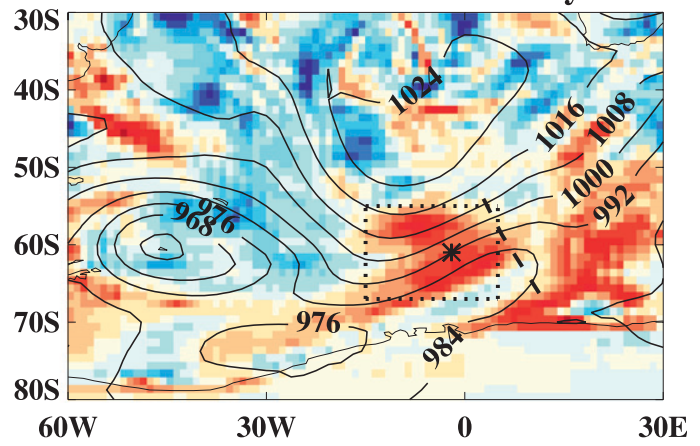

MIROC5

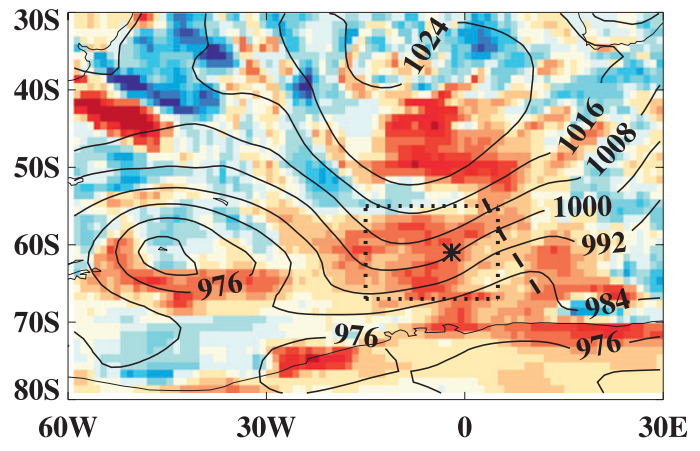

FIG. 6. A 24-h mean bias in RSW against CERES-Flashflux for 17 Jan 2009 in hindcasts initialized at 0600 UTC 16 Jan 2009. Contours show model forecast MSLP at 1200 UTC 17 Jan 2009 at 8-hPa intervals. Dotted box and asterisk mark a region and point analyzed in this study. Dashed line marks the overpass of the satellite A-Train at approximately 1420 UTC 17 Jan 2009.

Again, consistent with the COSP diagnostics from the models used for the ISCCP comparison, the CALIPSOsimulated histograms produced by COSP for CNRMCM5 and HadGEM2-A show the cloud top to be too low in the models and too optically thin, indicated by the lower scattering ratio than observed (Figs. 8c,d).

\section{b. Boundary layer structure}

Given that the models appear to generally share a bias of the boundary layer cloud being too low and insufficiently reflective, we now examine the boundary layer structure at a point $61^{\circ} \mathrm{S}, 2^{\circ} \mathrm{W}$, marked with an asterisk in Fig. 6.

The profiles of temperature and humidity from the ECMWF analysis at 1200 UTC 17 January 2009 are plotted in Fig. 9. The profile indicates a near saturated layer between 925 and $870 \mathrm{hPa}$. Above this is a strong temperature inversion with its top at $815 \mathrm{hPa}$ and a much dryer free troposphere above this. The profiles from the models verifying at the same time, $30 \mathrm{~h}$ into the hindcast, generally capture the presence of an inversion 

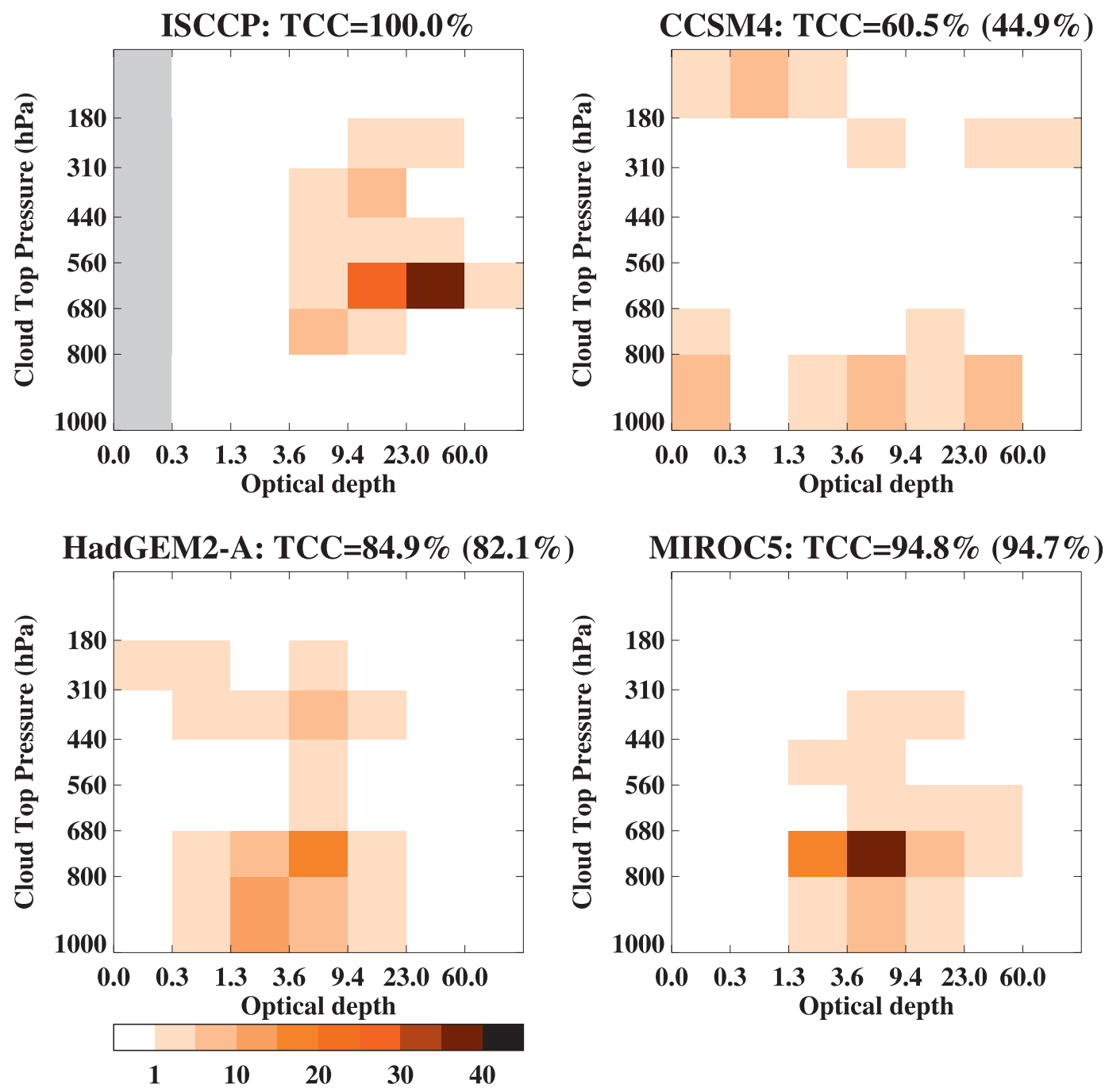

FIG. 7. Histograms of cloud fraction binned according to optical depth and cloud-top pressure as observed by ISCCP and from the model COSP output over the dotted box in Fig. 6. Comparison is for 1200 UTC 17 Jan 2009 from hindcasts initialized 0600 UTC 16 Jan 2009. The total cloud cover (TCC), which is the sum across the histogram, is given in the title of each histogram; the figure in brackets for the GCMs excludes optical depths less than 0.3 for a fairer comparison with ISCCP. (These diagnostics were unavailable for CNRM-CM5 and IPSL-CM5A-LR.)

with a dryer free troposphere, although the detail is often in error. In particular, all of the T-AMIP2 models have an inversion that is too low. Several of the models have a nearsaturated layer below the inversion that is less than half the physical thickness observed. In contrast, the boundary layer in CNRM-CM5 (and to a lesser extent CCSM4) appears warmer and so further from saturation, possibly accounting for the lower scattering ratio in Fig. 8 and higher RSW bias in Fig. 6 compared with the other models. IPSLCM5A-LR, although having a cooler boundary layer than the EC analysis, has the thickest layer that is close to saturation out of the T-AMIP2 models and has the highest inversion base of these models. This may well be associated with the smaller RSW bias for IPSL-CM5A-LR in Fig. 6.
These common biases in the boundary layer structure are consistent with the cloud biases, and indicate that the inversion being too low is related to the cloud being lower than observed. The saturated layer being physically thinner than observed may, at least in part, also be associated with the cloud optical depths and scattering ratios being too low.

To investigate the development of these errors in the boundary layer structure we make use of the temperature tendency diagnostics requested by T-AMIP2. We now examine the early stages of the hindcast initialized at 1200 UTC 17 January 2009 (the verification time of profiles shown in Fig. 9). Since the models are starting from an alien analysis, there is often a significant 
a) CALIPSO backscatter ratio

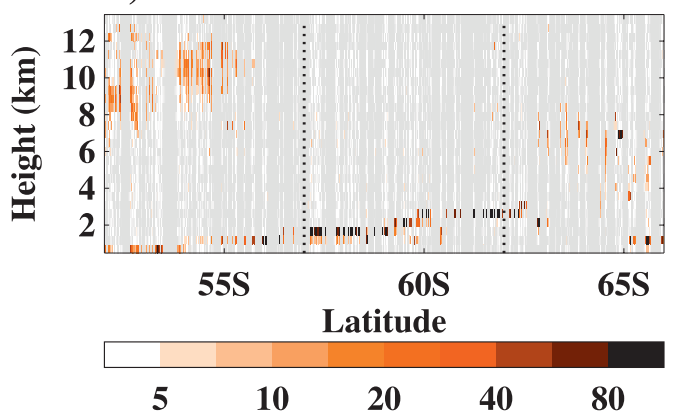

c) Height-Lidar SR Histogram CNRM-CM5

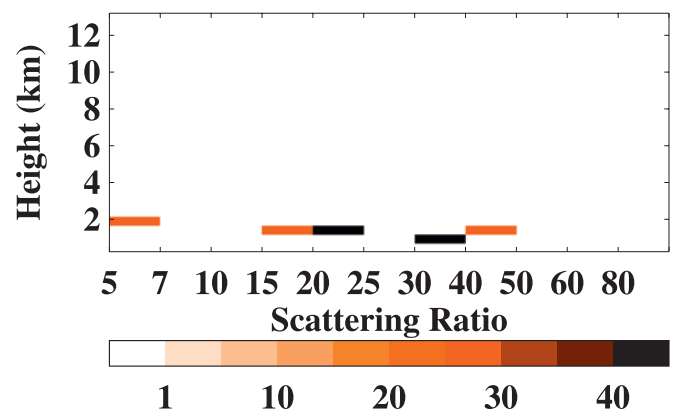

b) Height-Lidar SR Histogram CALIPSO

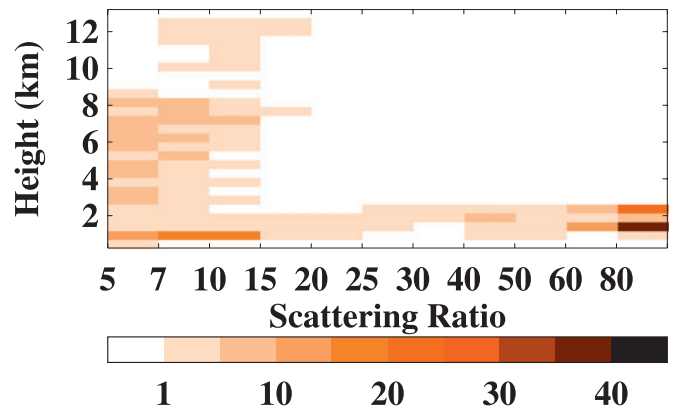

d) Height-Lidar SR Histogram HadGEM2-A

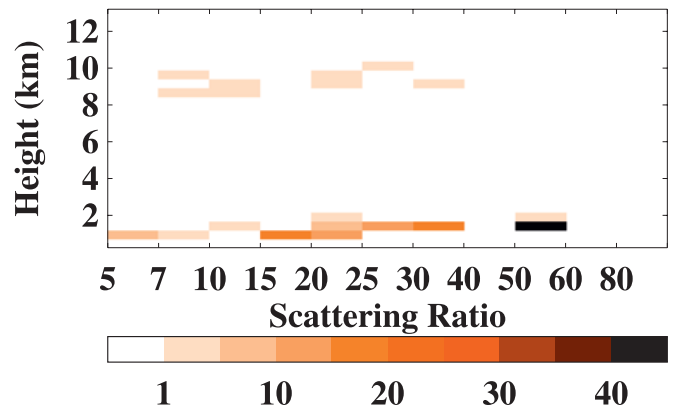

FIG. 8. (a) Curtain showing observed CALIPSO backscatter ratio along the transect shown (dashed) in Fig. 6; gray columns are "missing data." Also shown are histograms of cloud fraction binned according to scattering ratio and altitude for the section of the transect between the dotted lines in (a): (b) the CALIPSO observed histogram and (c),(d) model COSP output for the same section. (These diagnostics were unavailable for CCSM4, IPSL-CM5A-LR, and MIROC5.)

adjustment of schemes in the first time step, while the noninitialized prognostic variables (e.g., cloud) spin up. This can affect the first 3-h mean tendency, but subsequent tendencies are found to be more consistent and show some common behaviors among the models. Figure 10 shows the mean temperature tendencies between 3 and $6 \mathrm{~h}$ into the hindcast. The total temperature tendency (solid black) indicates that the models all have a warming tendency at altitudes above $890 \mathrm{hPa}$. The level that this warming extends down to varies between the models from $890 \mathrm{hPa}$ in IPSL-CM5A-LR to the surface in CCSM4. The other models have a slight cooling tendency near the surface. During this period the environment in the real world will be evolving and so we take the difference between successive ECMWF analyses to estimate the "observed" tendency for the point (dashed black). This also shows a warming peaking at around $870 \mathrm{hPa}$, but this changes to a cooling at altitudes below $890 \mathrm{hPa}$. Hence we have a picture that during the afternoon of 17 January the inversion at this point is becoming stronger, but in CCSM4, HadGEM2-A, and MIROC5 the warming is extending too far down. IPSL-CM5A-LR is closer to the observed tendency, consistent with the higher inversion base for this model in Fig. 9.

T-AMIP2 requests tendency diagnostics from various sections of the model physics/dynamics, enabling the evolution of the total tendency to be examined. These sections are shown as colored lines in Fig. 10 and the gray line shows their sum. This sum may not always be identical to the total tendency because of the effect of other model-specific aspects of the model science on the temperature, but should usually be close. It can be seen that much of the anomalous warming in MIROC and HadGEM2-A below $890 \mathrm{hPa}$ is coming through the advection. It should be noted, though, that the error in the total tendency may be due to an insufficient compensating cooling effect from other processes. Indeed, this is suggested in IPSL-CM5A-LR where there is a similar warm advection around $900 \mathrm{hPa}$, but it is being balanced by radiative cooling. It is likely that this radiative cooling is coming from the thicker cloud sheet in this model; hence, there appears to be an important and sensitive feedback between the cloud and the boundary layer structure in the first few hours of the model 


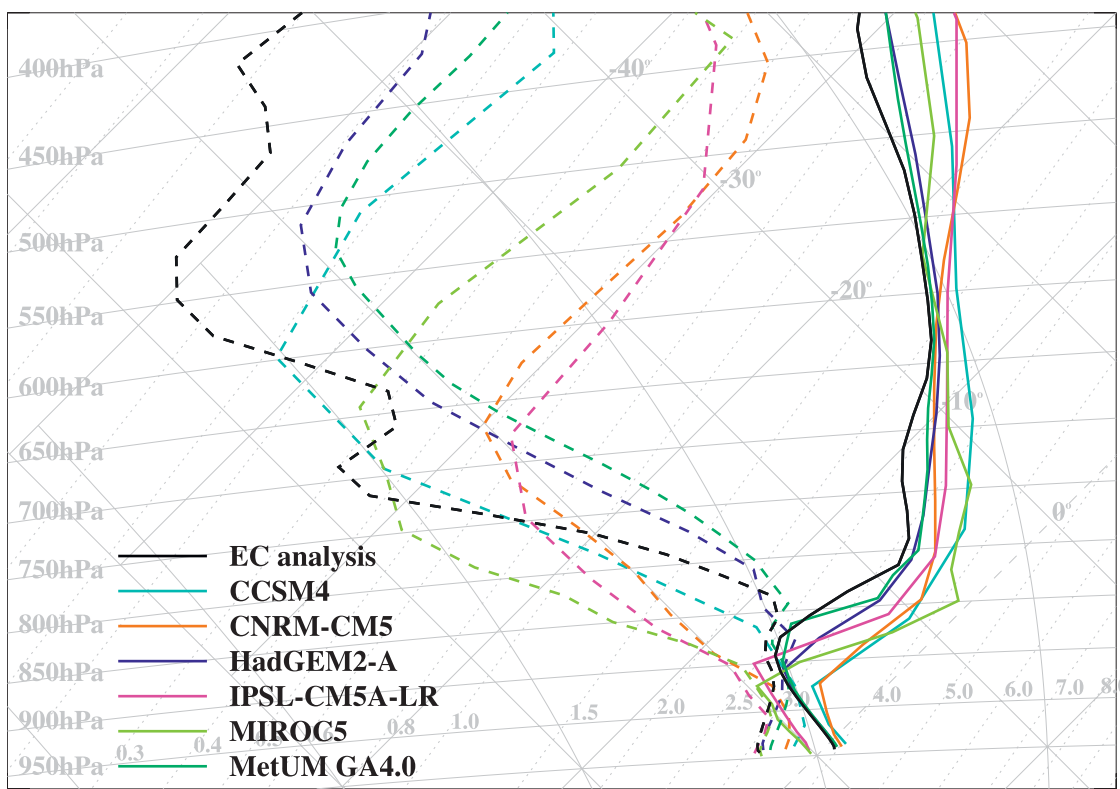

FIG. 9. Standard U.K. tephigram showing vertical profiles of temperature (solid) and humidity (dashed) at the point marked by the asterisk in Fig. 6. Profiles for the T-AMIP2 models are for 1200 UTC 17 Jan 2009 from hindcasts initialized at 0600 UTC 16 Jan 2009. Also shown is the same hindcast from a more recent configuration of the Met Office model (MetUM GA4.0), together with the ECMWF analysis profile for 1200 UTC 17 Jan 2009.

simulation. If the cloud layer is not maintained sufficiently strongly, then the boundary layer structure will evolve, thinning the cloud further.

Given this sensitivity, accurate representation of the details of the boundary layer structure is likely to be important, but the vertical resolution of these models is too coarse to resolve the details of the inversion. The position of the model levels has been marked on the right side of each panel in Fig. 10. IPSL-CM5A-LR appears to maintain the cloud layer and inversion height with relatively coarse resolution; however, even this model has errors in the temperature structure, being too cold in the boundary layer (Fig. 9). For HadGEM2-A in particular, it can be seen that the lack of vertical resolution may be a factor in the lower inversion height since the temperature tendencies at the model level points are close to those observed, but the spacing of the levels means that the gradient between the warming and cooling is not strong enough (Fig. 10). We have rerun the hindcast initialized at 0600 UTC 16 January with a more recent configuration of the Met Office Unified Model (MetUM) using the Global Atmosphere 4 (GA4) science (D. N. Walters et al. 2013, unpublished manuscript). Many aspects of this model have changed since HadGEM2-A including a new cloud scheme and significant developments to the boundary layer scheme. However, one of the largest impacts on the simulation of cloud globally was the introduction of higher vertical resolution (from
38 to 85 levels). In particular, MetUM GA4 has almost twice the number of levels between the surface and $700 \mathrm{hPa}$ as HadGEM2-A. The hindcast has been rerun following the T-AMIP2 protocol, initialized from ECMWF analyses and run at the same horizontal resolution as HadGEM2-A.

Temperature and humidity profiles for MetUM GA4 $30 \mathrm{~h}$ into the hindcast have been added to Fig. 9. While there are still differences with respect to the ECMWF analyses, it can be seen that the model captures the boundary layer structure-the inversion and nearsaturated layer below-much better than HadGEM2-A. It is very likely that improved representation of the inversion in this case has been enabled through the higher vertical resolution. Consistent with this improved boundary layer structure is that the RSW bias has been almost halved for the region being studied here (cf. Fig. 11 with HadGEM2-A in Fig. 6).

\section{Conclusions}

In this paper we have presented the T-AMIP2 experiment: a coordinated model intercomparison project, running alongside CMIP5, in which climate models are run in "weather forecast mode," initialized from a common analysis. The aim of the project is to permit detailed diagnostic investigations into the processes operating in models being used for climate change projections in 
CCSM4

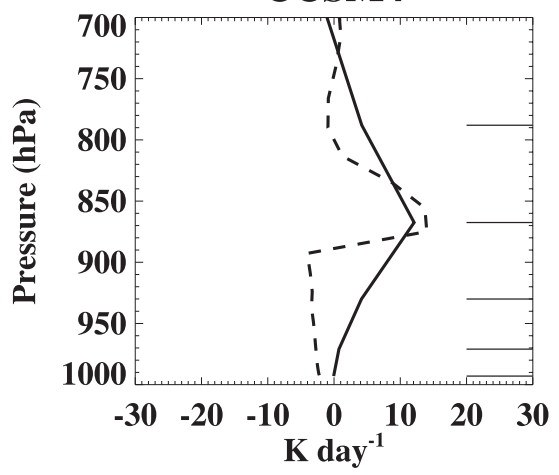

IPSL-CM5A-LR

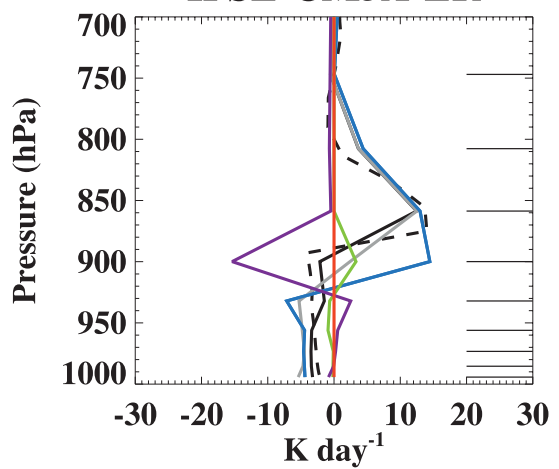

HadGEM2-A
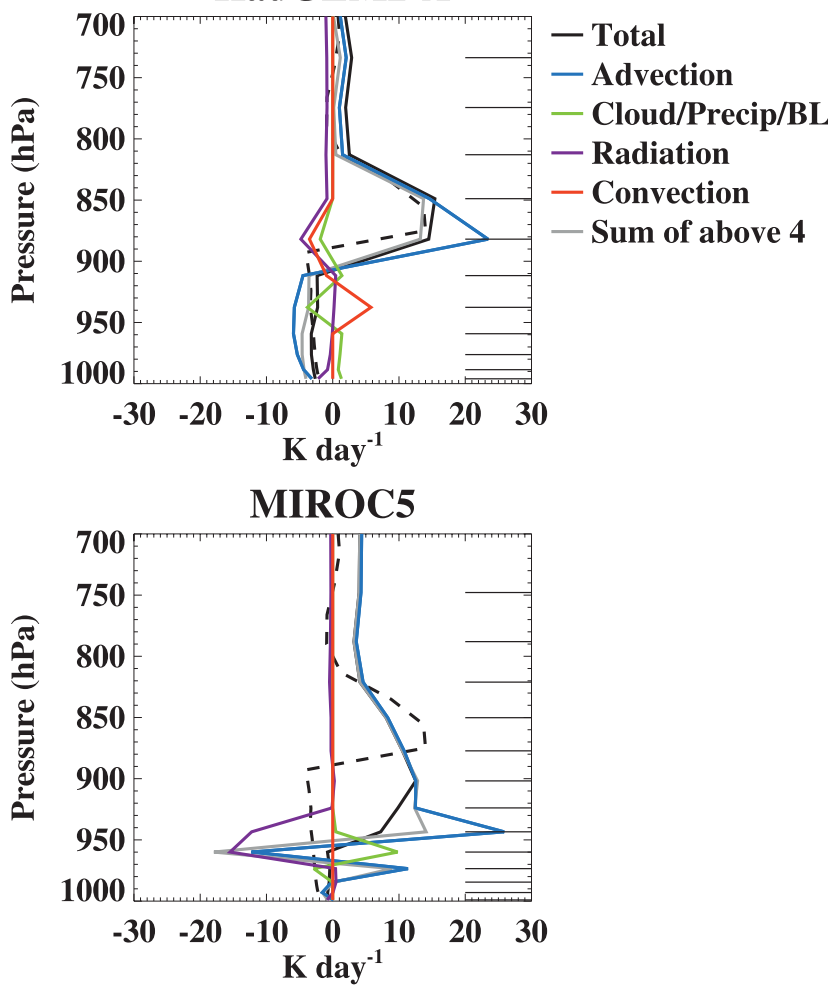

FIG. 10. Mean temperature tendencies between 3 and $6 \mathrm{~h}$ into the hindcast initialized at 1200 UTC 17 Jan 2009. Total and component tendencies from various sections of the model physics/dynamics are shown. Dotted line shows the temperature tendency between the 1200 and 1800 UTC ECMWF analyses. Horizontal lines on the right side of each panel mark the positions of the model levels. (These diagnostics were unavailable for CNRM-CM5. Only the total tendency was available for CCSM4.)

CMIP5. To fulfill this aim, T-AMIP2 requests a comprehensive set of diagnostics including satellite simulator and tendency diagnostics at high temporal resolution, plus near-time-step diagnostics at a selection of sites. The set of hindcasts has been chosen to tie in with IOPs within a number of field campaigns, and is all set within the intensively studied YOTC period.

The use of some of these diagnostics for detailed investigations has been illustrated in an analysis of TOA flux biases over the Southern Ocean. This is an issue for many GCMs and is believed to affect their coupled atmosphereocean performance and climate change response. Most of the models submitted to T-AMIP2 share a bias of too little RSW over the Southern Ocean, although details vary and IPSL-CM5A-LR is notably different in having a positive bias. The negative RSW bias has been shown to be present primarily on the cold-air side of cyclones and/or leading side of transient ridges, away from frontal regions. The bias is present when the lower troposphere is more stable, but it can be associated with a range of low-level wind speeds.

A case study has been presented that is typical of the conditions under which an RSW bias is present in all of the models. Generally, the biases are more similar between the models at these short ranges. Variations in the climatological bias then develop due to differences in the magnitude of positive and negative biases in different

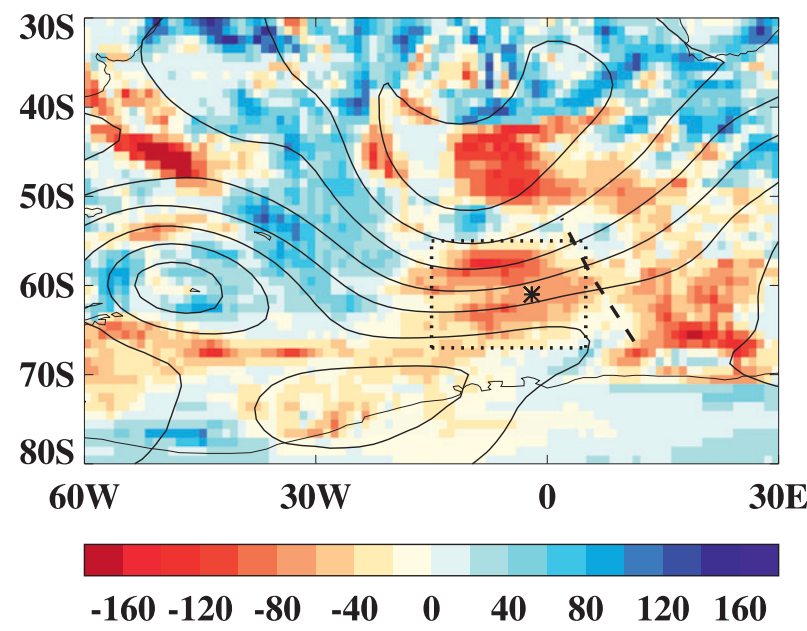

FIG. 11. As in Fig. 6, but for MetUM GA4.0. 
synoptic conditions and, in some models, due to longer time-scale feedbacks. Investigation of the T-AMIP2 hindcasts for the case study has revealed that the bias develops quickly (within the first day) and is primarily due to the cloud being too optically thin, with an additional contribution from the cloud fraction being too low in some models. It appears that the overly thin stratocumulus is associated with the inversion being quickly lowered at the beginning of the hindcast and a physically thinner cloud layer being produced.

This type of boundary layer appears to be problematic for all of the models investigated and examination of model tendencies over the first few hours of the hindcast suggests that the GCMs can be sensitive to a positive feedback process between the removal of cloud and evolution of the boundary layer structure. Details of the exact cause of the errors in the boundary layer structure and cloud are likely to vary from model to model and could well have more than one source. However, identifying the conditions under which models develop the bias should assist model developers in each center in investigating further and focus improvements to the science in their model. In at least one model, the lack of sufficient vertical resolution to properly represent the boundary layer temperature and humidity structure appears to be a factor. In a more recent configuration of this model, with almost double the vertical resolution in the boundary layer, the RSW bias is significantly reduced.

This is the first T-AMIP2 study; however, there are a very large number of other studies that could potentially be carried out with T-AMIP2 data. The data are freely available for use by the research community and we encourage scientific researchers to conduct their own investigations. Several modeling centers have indicated that they intend to submit T-AMIP2 data over the coming year and we are confident that more will follow. We believe that a set of detailed diagnostic investigations using these data will lead to a greater understanding of which processes we have confidence in and which require a more focused effort to improve in the current generation of climate models.

Acknowledgments. This work was supported by the Joint DECC/Defra Met Office Hadley Centre Climate Programme (GA01101).

The contributions of B. Medeiros and D. Williamson to this work were supported by the Office of Science (BER), U.S. Department of Energy, Cooperative Agreement DE-FC02-97ER62402.

The contribution of S.A. Klein to this work was supported by the Regional and Global Climate Modeling and Atmospheric System Research Programs of the Office of Science at the U.S. Department of Energy and was performed under the auspices of the U.S. Department of Energy by Lawrence Livermore National Laboratory under Contract DE-AC52-07NA27344.

We acknowledge WGNE and WGCM, who are responsible for T-AMIP2 and CMIP5, and we thank the climate modeling groups listed in section 3 for producing and making available their model output. For CMIP5 and T-AMIP2 the U.S. Department of Energy's Program for Climate Model Diagnosis and Intercomparison provides coordinating support and led development of software infrastructure in partnership with the Global Organization for Earth System Science Portals.

CERES, ERBE, and ISCCP data were obtained from the NASA Langley Research Center Atmospheric Sciences Data Center. CALIPSO-GOCCP data were obtained from the IPSL ClimServ data centre (http://climserv. ipsl.polytechnique.fr/cfmip-obs.html).

\section{REFERENCES}

Barkstrom, B. R., and G. L. Smith, 1986: The Earth Radiation Budget Experiment: Science and implementation. Rev. Geophys., 24, 379-390.

Bodas-Salcedo, A., and Coauthors, 2011: COSP: Satellite simulation software for model assessment. Bull. Amer. Meteor. Soc., 92, 1023-1043.

, K. D. Williams, P. R. Field, and A. P. Lock, 2012: The surface downwelling solar radiation surplus over the Southern Ocean in the Met Office model: The role of midlatitude cyclone clouds. J. Climate, 25, 7467-7486.

Boyle, J., and S. A. Klein, 2010: Impact of horizontal resolution on climate model forecasts of tropical precipitation and diabatic heating for the TWP-ICE period. J. Geophys. Res., 115, D23113, doi:10.1029/2010JD014262.

, and Coauthors, 2005: Diagnosis of Community Atmospheric Model 2 (CAM2) in numerical weather forecast configuration at Atmospheric Radiation Measurement sites. J. Geophys. Res., 110, D15S15, doi:10.1029/2004JD005042.

Brown, A. R., S. Milton, M. Cullen, B. Golding, J. Mitchell, and A. Shelly, 2012: Unified modeling and prediction of weather and climate: A 25-year journey. Bull. Amer. Meteor. Soc., 93, 1865-1877.

Chepfer, H., S. Bony, D. Winker, G. Cesana, J.-L. Dufresne, P. Minnis, C. J. Stubenrauch, and S. Zeng, 2010: The GCM-oriented CALIPSO cloud product (CALIPSO-GOCCP). J. Geophys. Res., 115, D00H16, doi:10.1029/2009JD012251.

Field, P. R., and R. Wood, 2007: Precipitation and cloud structure in midlatitude cyclones. J. Climate, 20, 233-254.

Gates, W. L., and Coauthors, 1999: An overview of the results of the Atmospheric Model Intercomparison Project (AMIP I). Bull. Amer. Meteor. Soc., 80, 29-55.

Gent, P. R., and Coauthors, 2011: The Community Climate System Model version 4. J. Climate, 24, 4973-4991.

Haynes, J. M., C. Jakob, W. B. Rossow, G. Tselioudis, and J. Brown, 2011: Major characteristics of Southern Ocean cloud regimes and their effects on the energy budget. J. Climate, 24, 5061-5080.

Illingworth, A. J., and Coauthors, 2007: Cloudnet: Continuous evaluation of cloud profiles in seven operational models using groundbased observations. Bull. Amer. Meteor. Soc., 88, 883-898. 
Loeb, N. G., B. A. Wielicki, D. R. Doelling, S. Kato, T. Wong, G. L. Smith, D. F. Keyes, and N. Manalo-Smith, 2009: Toward optimal closure of the earth's top-of-atmosphere radiation budget. J. Climate, 22, 748-766.

Martin, G. M., S. F. Milton, C. A. Senior, M. E. Brooks, S. Ineson, T. Reichler, and J. Kim, 2010: Analysis and reduction of systematic errors through a seamless approach to modeling weather and climate. J. Climate, 23, 5933-5957.

—_, and Coauthors, 2011: The HadGEM2 family of Met Office Unified Model climate configurations. Geosci. Model Dev., 4, 723-757, doi:10.5194/gmd-4-723-2011.

Medeiros, B., D. L. Williamson, C. Hannay, and J. G. Olson, 2012: Southeast Pacific stratocumulus in the Community Atmosphere Model. J. Climate, 25, 6175-6192.

Neale, R. B., and Coauthors, 2010: Description of the NCAR Community Atmosphere Model (CAM 4.0). NCAR Tech. Note NCAR/TN-485+STR, 224 pp. [Available online at http:// www.cesm.ucar.edu/models/ccsm4.0/cam/docs/description/ cam4_desc.pdf.]

Norris, J. R., and C. P. Weaver, 2001: Improved techniques for evaluating GCM cloudiness applied to the NCAR CCM3. J. Climate, 14, 2540-2550.

Phillips, T. J., and Coauthors, 2004: Evaluating parameterizations in general circulation models: Climate simulation meets weather prediction. Bull. Amer. Meteor. Soc., 85, 1903-1915.

Rienecker, M. M., and Coauthors, 2011: MERRA: NASA's Modern-Era Retrospective Analysis for Research and Applications. J. Climate, 24, 3624-3648.

Rodwell, M. J., and T. N. Palmer, 2007: Using numerical weather prediction to assess climate models. Quart. J. Roy. Meteor. Soc., 133, 129-146, doi:10.1002/qj.23.

Rossow, W. B., and R. A. Schiffer, 1999: Advances in understanding clouds from ISCCP. Bull. Amer. Meteor. Soc., 80, 2261-2287.

Senior, C. A., and Coauthors, 2010: Synergies between numerical weather prediction and general circulation climate models. The Development of Atmospheric General Circulation Models: Complexity, Synthesis, and Computation, L. Donner, R. Somerville, and W. Schubert, Eds., Cambridge University Press, 76-116.

Taylor, K. E., R. J. Stouffer, and G. A. Meehl, 2012: An overview of CMIP5 and the experiment design. Bull. Amer. Meteor. Soc., 93, 485-498.
Trenberth, K. E., and J. T. Fasullo, 2010: Simulation of present-day and twenty-first-century energy budgets of the southern oceans. J. Climate, 23, 440-454.

Voldoire, A., and Coauthors, 2013: The CNRM-CM5.1 global climate model: Description and basic evaluation. Climate Dyn., doi:10.1007/s00382-011-1259-y, in press.

Waliser, D. E., and Coauthors, 2012: The "Year" of Tropical Convection (May 2008-April 2010): Climate variability and weather highlights. Bull. Amer. Meteor. Soc., 93, 1189-1218.

Watanabe, M., and Coauthors, 2010: Improved climate simulation by MIROC5: Mean states, variability, and climate sensitivity. J. Climate, 23, 6312-6335.

Wielicki, B., B. R. Barkstrom, E. F. Harrison, R. B. Lee, G. L. Smith, and J. E. Cooper, 1996: Clouds and the Earth's Radiant Energy System (CERES): An earth observing system experiment. Bull. Amer. Meteor. Soc., 77, 853-868.

Williams, K. D., and M. E. Brooks, 2008: Initial tendencies of cloud regimes in the Met Office Unified Model. J. Climate, 21, 833-840.

—_, and Coauthors, 2006: Evaluation of a component of the cloud response to climate change in an intercomparison of climate models. Climate Dyn., 26, 145-165, doi:10.1007/s00382-005-0067-7.

Williamson, D. L., and Coauthors, 2005: Moisture and temperature balances at the Atmospheric Radiation Measurement Southern Great Plains site in forecasts with the Community Atmosphere Model (CAM2). J. Geophys. Res., 110, D15S16, doi:10.1029/2004JD005109.

Winker, D. M., and Coauthors, 2010: The CALIPSO mission: A global 3D view of aerosols and clouds. Bull. Amer. Meteor. Soc., 91, 1211-1229.

Xie, S., H.-Y. Ma, J. S. Boyle, S. A. Klein, and Y. Zhang, 2012: On the correspondence between short- and long-time-scale systematic errors in CAM4/CAM5 for the Year of Tropical Convection. J. Climate, 25, 7937-7955.

Zhang, Y.-C., W. B. Rossow, A. A. Lacis, V. Oinas, and M. I. Mishchenko, 2004: Calculation of radiative fluxes from the surface to top of atmosphere based on ISCCP and other global data sets: Refinements of the radiative transfer model and input data. J. Geophys. Res., 109, D19105, doi:10.1029/ 2003JD004457.

Zhang, Y.-Y., S. A. Klein, J. Boyle, and G. G. Mace, 2010: Evaluation of tropical cloud and precipitation statistics of CAM3 using CloudSat and CALIPSO data. J. Geophys. Res., 115, D12205, doi:10.1029/2009JD012006. 